\title{
Obituaries
}

\section{W. Kilmister 1924-2010}

Clive William Kilmister was born in Epping in 1924, the son of a wood pattern maker. He attended Leytonstone County School and then, in 1942, Queen Mary College which at the time was evacuated to King's College Cambridge. He graduated with first class honours just two years later, winning the Sherbrooke Studentship and having also done military service in the Royal Artillery. On the recommendation of C. P. Snow he then spent three years at Plessey's working on radar development. He returned to QMC in 1947, taking an MSc by examination in 1948, on the theory of complex functions and electromagnetic theory, and beginning research under the cosmologist George McVittie, himself a former student of Arthur Eddington and Edmund Whittaker. In the same year he met Peggy Hutchins, who was reading English at QMC, and they married in 1955.

Clive's work for the $\mathrm{PhD}$ involved the algebraic theories of Eddington, and the study of Eddington's work occupied him at times throughout his career. He was awarded the PhD in 1950 for his thesis entitled 'The use of quaternions in wave-tensor analysis', and he was appointed assistant lecturer at King's College London the same autumn. This post, since abolished, was a fixed term one for three or possibly four years, after which the holder was expected to leave. As Clive put it, he was 'saved' by being appointed lecturer in 1953, and he remained at KCL for the rest of his working life, being promoted reader in 1959, and professor in 1966. He retired in 1984, but remained active mathematically for another quarter-century.

In later years Clive recalled the small department he joined as being a very happy place. Departmental bureaucracy was essentially confined to a half hour meeting after the summer examinations although, as he said, it did sometimes run over to nearly three quarters of an hour. In 1954 Hermann Bondi joined the Department and, together with Clive and Felix Pirani, established the gravitational theory group. The King's group quickly became internationally renowned. It was one of a small number largely responsible for the postwar renaissance of research into Einstein's theory of general relativity.

During Clive's stay at KCL he supervised about two-dozen research students, mostly for the PhD degree. He had broad interests, and his publications range over Eddington's work and applications of his algebraic approach in other fields, and also general relativity and unified field theories, special relativity, mechanics (including quantum mechanics) both in relation to teaching and foundations, history and philosophy of science, and applications of mathematics in the social sciences. With his long-term collaborator Ted Bastin he was involved in attempts to construct an abstract approach to physics, and they were founding members of the Alternative 
Natural Philosophy Association. This latter work he regarded as his most important and the most likely to endure, though perhaps also his most heterodox. He was author of more than a dozen books, the last of which, 'The Origin of Discrete Particles' (with E. W. Bastin) appeared in 2009.

He was active in many other directions. He was a member of the Mathematical Association committee which reported on the teaching of modern mathematics in 1962, and of another dealing with the teaching of mechanics in schools which reported in 1965 . He was President of the Mathematical Association from 1979-1980. He was a member of the committee of the British Society for the Philosophy of Science from 19631966 and President from 1981-1983. He was a member of the committee of the British Society for the History of Mathematics on two occasions, and President from 1975-1976. He was Gresham Professor of Geometry from 1972-1988. Readers of the Gazette will know his regular book reviews, the last of which appeared posthumously in July this year; back in the 1970s he produced weekly (it seemed) reviews for the Times Higher Education Supplement, and the lifetime collection of books he had reviewed occupied some thirty feet of shelf space in his house.

At King's College, over the years, Clive taught courses on a huge variety of topics. His lectures were clear, well thought-out, and somewhat idiosyncratic. His students loved him, though his relaxed style sometimes misled them into thinking the examination was likely to be somewhat easier than tumed out to be the case. Hermann Bondi was very interested in teaching, and he got Clive and Felix Pirani to assist him in giving short vacation courses for students. This was probably the starting point of Clive's interest in teaching, where one of his main concerns was to try to improve the quality of preparation of first-year undergraduates, witness his involvement in the MA committees mentioned above. His Presidential Address to the Association, which appeared (with his photograph) in the October 1980 issue of the Gazette, was entitled 'Zeno, Aristotle, Weyl and Shuard: two-and-a-half millennia of worries over number'. In it, he examined continuing difficulties over teaching analysis to first-year undergraduates, who were 'making their first genuine acquaintance with the real number field'. Having looked in some detail at the history of the topic, he summed up his deliberations as follows:

'I think there is a moral in this for all our teaching, and not only in analysis for first-year undergraduates. It is this: if, year after year, they seem to find a particular difficulty with something, it may be because the difficulty is really there. Our modern axiomatic method is very powerful, but it has a power which can sometimes be used to sweep difficulties under the carpet. And a study of history can help by indicating when the danger of this is present.'

Clive was noted for his willingness to undertake large administrative tasks, which he discharged amiably and efficiently, to the admiration and gratitude of his colleagues. He chaired examination boards for the university, where he succeeded in cutting meetings to a reasonable length by 
introducing what became known jocularly as Kilmister's rule, which in essence stopped the then current practice of reading out loud the results of every single candidate and concentrated instead on borderline cases. In the Department there was a convention that each examination question was initially marked out of 50 'raw marks' (to encourage the award of partmarks) before being re-scaled; Clive had no patience with this and got around it by only awarding part-marks in multiples of five. (His secondmarker was scandalized and re-marked a pile of scripts, but found that the grades he was awarding agreed exactly with Clive's.) By the time he retired, Clive had been Dean of the Faculty of Natural Science, and was Head of the Department of Mathematics.

I have many reasons to be grateful to Clive. As a young lecturer I quickly realised that he was among the most approachable, generous and helpful of my senior colleagues, and I picked his brains and benefited from his advice on innumerable occasions. He encouraged me early on to take an interest in what went on in schools by arranging for me to be involved in examining for the London Teaching Certificate and, much later, by suggesting I might like to become Admissions Tutor. And, knowing that I lived a long way out from London, year after year he so organized the timetable that I could avoid too often having to travel uncomfortably and expensively in the rush-hour.

Clive was a devoted husband and family man. He and Peggy shared interests in theatre, opera, art, and music, in particular lieder. After retirement they moved from London to what had been their weekend cottage, in Sussex, and as noted above, Clive continued to work and to write. He sometimes suffered from insomnia, and would do mathematics to pass away the hours of darkness, and occasionally I would get a letter from him with a geometrical query which might start me off in a new direction. He died peacefully at home on 2 May 2010, after a year of battling with cancer. He is survived by Peggy, their three children Andrew, Sally and Penny, and by four grandchildren, Helena, Ben, Miriam and Isa.

I wish to thank my colleagues David Robinson and Mike Laird for help with this notice, and also Peggy and Andrew Kilmister for their correspondence, and for making available to me Clive's own notes on his many activities.

JOHN R. SILVESTER

Department of Mathematics, King's College, Strand, London WC2R $2 L S$ e-mail:jrs@kcl.ac.uk 